\title{
Study on the Situation and Strategies of the Elderly People Sports Activities in the Grass-root Communities
}

\author{
Xiuling Zhang' a \\ ${ }^{1}$ Zhengzhou Technical College, Zhengzhou, Henan, China, 450000 \\ ${ }^{a}$ email
}

Keywords: Urban Community, The Elderly, The Elderly Culture, Self - help Pension

\begin{abstract}
With the rapid growth of the elderly population in China, the living conditions of the elderly people attract increasingly attention. They are eager to rich and colorful cultural life, have a strong spiritual and cultural needs, the development of community culture of the elderly has become the social needs. Community workers should focus on the elderly, find out the characteristics of the elderly, according to the needs of the elderly, targeted and organized to carry out a series of activities to fully tap the potential of the elderly, give full play to the old subjective initiative, passive to active, take pressure as the driving force, take a public welfare and commercial combination the road, take a self-pension and social old-age combination road.
\end{abstract}

\section{Introduction}

Aging of population is the inevitable trend of social development in our country, and it is also the giant war we must face in building a harmonious socialist society. The elderly are an important part of our society, and their living conditions are directly related to the level of social development, and their relationship directly affects the degree of social harmony. At present, the number of the elderly population of more than 160 million, with the 20th century, the peak population born in the 1950s have entered the elderly, is expected to 2015, the total number of elderly people in China will exceed 200 million people. With the development of Chinese social economy, urban pension insurance system is maturing and the basic needs of the basic needs of the elderly have been met. But today the elderly have not only satisfied with the food and clothing, they desire a rich cultural life, has a strong spiritual and cultural needs. Vigorously develop the elderly culture, for the elderly to provide a good spiritual living environment, cultural products and services are imperative. Elderly people are a special social group, a pioneer in social development, but also a great pressure on social development. In particular, the urban elderly, they basically receive a pension, and enjoy the national pension insurance. They are free, but they are also fragile. They need special protection of society, the need for special social care. The urban elderly are basically based on community-based living patterns and they are in the community for most of the daily activities. Therefore, in the city, the responsibility for special protection and care for the elderly is more on the shoulders of the community. At the same time, the problem of the elderly is one of the key factors restricting the development of the community. The living condition of the elderly directly affects the community and affects the harmonious degree of the community. Therefore, it is necessary to explore how to develop the elderly culture to find out how to better improve the community work, how to better promote community harmony.

\section{The General Situation of Chinese Aging Society}

According to the 2009 Statistical Bulletin on the Development of Aging in China, the number of elderly people aged over 60 in China reached 167.14 million in 2009, 12.5\% of the total population. Compared with the previous year, the net increase of the elderly was 7.25 million, an increase of 0.5 percentage points. Of which 80 years old and older to 18.99 million, accounting for $11.4 \%$ of the proportion of the elderly population. And it can be predicted that Chinese elderly will continue to grow rapidly. At this stage, Chinese old-age pension model is mainly home care and institutional pension and community pension three models, if the family is the main living areas of the elderly, 
then the family where the community is their second life in the second space. Old age is generally a leisure life, but due to physical recession, their activities are subject to very limited space. Chinese "sample survey of the situation of the elderly in nine cities," shows that urban elderly in the vicinity of a year often account for $50.1 \%, 65.5 \%$ of the activities at the door, often in the city activities accounted for $15.6 \%$ City activities to the field accounted for only $1.4 \%$, indicating that most of the daily activities of the elderly is within the residential community. In other words, the vast majority of the elderly living space in addition to the family is the community [3]. But the elderly is a special group of members of society, is a member of the disadvantaged groups. With age, they are in the physical, psychological changes has taken place in a unique. Especially the psychological change on the health of the elderly has a profound impact on the needs of the community's attention.

At this stage, the psychological characteristics of the elderly in urban areas mainly in: In the past dozens of alternating spring and autumn, their hard work, successful career, respected and loved by the people. But after retirement, their social role has changed, the glory of the past is no, the former is no longer busy, and now the life becomes deserted, a day like, monotonous. In this gap, the elderly will inevitably be lost and it will inevitably be filled with emotion, dejected.

This is mainly for two reasons, first, because after leaving the workplace and the communication between colleagues less, past communication activities are not, and now life is very idle, or even doing nothing. Second, because the children are far away or separate the portal, and in this empty house, leaving only the old couple together, and even many have become empty-nest elderly. In these two areas under the influence of the elderly are often caught in Tokgo.

As the physiological function of the elderly declining, the resistance to disease gradually decreased and the elderly fear of disease-ridden. At the same time, the "twilight", "little time" the growing sense of decline. The lack of security of the elderly often becomes restless.

Want to change. The psychological characteristics of the elderly to the existing living conditions are not satisfied, they desire to communicate, eager to contact, eager to enrich themselves and eager to own life can be more colorful.

The problem of the elderly is a challenge that can not be neglected in the economic and social development of our country. At present, the living condition of the elderly is not optimistic, and the old people's physiological and psychological qualities are urgently needed to be improved. The old people are very aware of their own needs, for the spiritual and cultural consumption has a strong demand, which makes the present stage of our society there is a growing demand for older cultural and backward social and cultural systems between the deep contradictions. Community old-age support is a supplementary way of family support for the aged. It is a necessary complement or substitute for the weakening or lacking function of the old-age family in the modern family. Developing the old culture of the community not only can satisfy the cultural consumption needs of the elderly,

\section{The Status of Community Cultural Construction of the Elderly}

With the deepening of their own understanding of the elderly, their sense of autonomy is also growing. They strive to seek change, actively looking for the fun of life. According to the survey, the main activities of the elderly at this stage are: singing and dancing, chess, garden, flowers, grass, fish, bird, seal, root carving, collection, calligraphy, painting, writing, tourism, fitness Wait. Some are done on an individual basis, mainly in the form of family activities. Some are done collectively as a unit. This is mainly based on associations or universities for the elderly. At present, to participate in various associations or the elderly college education is sought after by many older people, and has achieved some success. This series of activities to enhance the quality of life of the elderly, promote social harmony and prosperity of the cultural market has played an important role. These activities mainly have the following characteristics:

Although a wide range of activities, but basically belong to the cultural context. Participate in cultural and sports activities, not only to meet the cultural needs of older people, more importantly, is able to attract a wide range of elderly people to participate in. Culture has colorful content, more than any other activity to enrich the elderly in their later years of life. Its requirements for 
participants are very low, in line with the physiological and psychological aspects of the elderly conditions.

Traditional culture is profound, attracting a lot of old man focused on the traditional culture of rich and colorful, but also provides enough opportunities for every one interested in the elderly. At the same time, the modern old people are inevitably influenced by the modern cultural atmosphere, they also pursue the trend, but also enjoy the modern way of life brings comfort.

It can be developed strong. In recent years, the cultural development of the elderly is swift and violent, the diversity of activities has been continuously enriched, the impact of activities is also expanding and more and more elderly people enjoy the benefits of the cultural development of the elderly. The number of consumer groups determines how much the market can do, while the spending power of consumer groups determines the capacity of the market and try. According to the China Center for Research on Aging, 42.8 percent of the urban elderly have a deposit. The current annual pension, re-employment income, family and friends of the subsidy is up to 3000 to 400 billion RMB, which shows that Chinese aging industry, a huge market.

Old people to participate in various activities, the purpose also wanted to enrich their own old age life, let yourself enjoy a period of full of laughter, full of warm sunset time. And the elderly do not like young people, after all, energy is limited, can be simple on the simple, easy to easily, can be convenient on the convenience. However, this series of activities, after all, still in its infancy, there are many issues also need to take into account, mainly as follows:

Organization is not strong. According to their hobbies, Old people have independent choice, arbitrariness. There is no fixed time, no fixed place, and there are no certain rules of activity. Community workers also pay little attention to this guidance, organization and supervision, which makes the scale of activities can not be expanded, the impact of activities can not be improved.

Activities isolated and scattered. Activities within the community are scarce, allowing the elderly to have entertainment, a substantial number of full. The elderly do not have much energy for long-distance play and many older people are more inclined to stay at home. Although societies, societies, and universities for the elderly are growing rapidly, the members of the organization come from all sides and live in very small numbers in the same community. From the current stage of community activities, they can only meet at a particular time together, and time is limited. And the diversity of the community has also resulted in the fragmentation of the distribution of the community, with a community of old people were scattered to various places, weekdays in the community deserted situation is not difficult to explain.

Coverage is small. The diversity of the elderly determines the variety of activities, but not all of the elderly are involved. It can be said that most of the elderly do not have enough conditions for them to pursue their hobbies, many elderly people's lives are a single tedious, they are eager to participate, thus enriching their old age. But some do not have that economic conditions, and some do not have that kind of skills, and some eccentric, poor communication.

Not effective. From time to time, we will see the success of the cultural and sports activities such as calligraphy and painting exhibitions, and we will also hear several elderly people have made remarkable achievements. But after all, only a few people, the cultural atmosphere of the community is not strong, many elderly people do not enjoy the benefits of cultural and sports activities, their lives have not changed so much. Their spiritual and cultural needs are still far from being met. The development of elderly culture in line with the needs of the elderly physiological and psychological aspects is to solve the problem of old age the most effective and most convenient way.

At this stage, the elderly cultural development is rapid, by many elderly people respected, old culture has been generally recognized, and has maintained a good momentum of development. The cultural consumption of the elderly has a huge market potential, has a strong vitality. However, the development of the elderly culture lacks a good mechanism to guide, management, contradictions, which makes its own potential power is not effectively released, the benefits of old age culture has not been generally enjoyed. How can we regulate the development of the elderly culture, how to make it effective in serving the elderly, it needs to carefully explore and pursue. 


\section{Strengthen the Way of Community Culture Construction}

The development of old culture has a huge potential market, but also has a strong vitality. Community workers should fully understand the great significance of old culture in building a harmonious community. We should attach importance to the elderly in the ideological and cultural values. To actively create a good atmosphere of the elderly cultural consumption, the work when the responsibility to care when the obligation, and more publicity, and more support.

Community workers to carry out long-term planning, increase policy support and investment, improve infrastructure construction, cultural consumption for the elderly to provide the necessary platform. Provide the necessary platform for the elderly entertainment cultivation is the basic guarantee for the development of community culture of the elderly, but also to meet the cultural needs of older people to promote and promote the development of the elderly community culture an effective way, but also community workers should carry out the most practical and most specific jobs. Community workers can enrich the green coverage and create more community leisure places; can also increase fitness equipment, rich fitness programs to enhance the physical fitness of the elderly; can also build stone stool stone table to attract the elderly outdoor chess; can be widely set up reading window, to provide colorful newspapers, update frequency and so on.

Actively organized, targeted to carry out a variety of cultural and sports activities, enrich the old age of life. Community workers should strengthen the guidance and management of the elderly cultural and sports activities to the community as a place to community residents as the main body, from time to time to carry out a series of interesting, meaningful, competitive, cooperative and distinctive cultural and sports activities. Such as culinary competition, calligraphy, male, chess, hegemony, politics and some close to life, close to the actual athletic activities, so that the elderly in the competition entertainment, enrichment in the entertainment. At the same time, communities can be established according to local conditions of the community of elderly amateur cultural and artistic groups, to improve the organization of activities. The holiday is a community worker can effectively use the platform, festive festivals and warmth, is the ordinary days can not match. With traditional festivals, especially the Chung Yeung Festival, to carry out special activities, not only conducive to the rendering section

Day atmosphere, is conducive to cohesion of the people, but also help to reduce the loneliness and anxiety of the elderly, for the elderly to add color to old age life, but also conducive to the promotion of traditional Chinese culture, enhance the cultural quality of the elderly, more conducive to ensure the community Harmony, stability.

To strengthen the link between the community and the community, and vigorously run the elderly education, improve community style organization. The basic guarantee for the construction of the aged culture is the organization construction. Elderly cultural and sports organizations are the backbone of cultural activities for the elderly. The community should actively carry out the construction of the elderly cultural and sports organizations, relying on the regional center for the elderly and cultural centers to cultivate a number of old culture, sports backbone team, promote grass-roots cultural and sports activities for the elderly carried out. At the same time, the strength of a single community is limited, community staff, can strengthen the joint with other communities, the organization of large-scale cultural and sports activities of the elderly, active square culture and mass culture. But also can jointly develop the elderly universities to meet the aspirations of the elderly to continue their studies, but also help to provide more of the elderly talent, and fully tap the potential of the elderly and promote the rapid and healthy development of old age culture.

To actively introduce market mechanisms to strengthen the combination of public welfare and commercial, adhere to the industrialization of the road. The development of old-age culture requires extensive social support, especially in the economic support. The introduction of market mechanism and the operation of market mechanism to realize the economic value of old culture can effectively solve the dilemma of shortage of funds, and also provide a steady supply of manpower and material resources for the development of the aged culture. According to the data provided by the National Working Committee on Aging, the annual demand of the elderly market in China is 600 billion RMB, in 2010 will reach 1 trillion, and now Chinese elderly market has a strong demand for public 
services, Each year for the elderly to provide the product of less than 100 billion RMB, between supply and demand there is a huge business opportunities. Vigorously develop the old cultural industry, the commercial introduction of old age cultural undertakings, to strengthen the combination of public welfare and commercial, in line with the inevitable development of social needs, but also the elderly culture to maintain youthful vitality and maintain long-term development of the most effective way. The problem of aging will be the biggest challenge China will have to face in the next 20 years, and it will be a daunting task for community workers. The elderly group is a special and fragile group, but it is also a potential group, in order to fully tap the potential of the elderly, to passively take the initiative, the pressure as the driving force, we need to vigorously develop the elderly cultural industry. Vigorously develop the elderly cultural industry is the most effective, most convenient and most durable way to solve the problem of old age. Vigorously develop the elderly culture, can enrich the old age of life, enhance the cultural connotation of the elderly; also conducive to carry forward the traditional culture, harmonious community environment. Community workers should focus on the elderly, find out the characteristics of the elderly, according to the needs of the elderly, targeted and organized to carry out a series of activities to fully tap the potential of the elderly, give full play to the old subjective initiative, Passive to active, of pressure as the driving force, take a public welfare and commercial combination of the road, take a self-pension and social old-age combination of the road.

\section{Acknowledgements}

Project: the Achievements of 2006 Henan Science and Technology Department Soft Science and Technology Plan.

Project Fund No.: 162400410592.

\section{References}

[1] Sun Xueshi, Liu Xinyi. On the construction of a harmonious society in the construction of the elderly culture [C]. Chinese Society of Gerontology 2006 Geriatric Academic Forum Proceedings. Beijing: China Gerontological Society, 2006.

[2] Hu Chuqing. Sunrise industry service sunset-community service to help the elderly[N]. Middle-aged Times, 2008- 07- 02

[3] Jiang Shaoji, Lu Hanming, Zhang Yanling. Family Medicine Wikipedia. Preventive care articles. [G]. Middle-aged care. Shanghai: Shanghai Science and Technology Literature Publishing House, 1996.

[4] Chongqing City Planning Research Center. Old resources, a land yet to be developed [EB / OL]. [201 0- 1 0-20] http://www.cqghyj.cn/moreli st.php?type=li stnews\&nid=280\&i d=297. 